\title{
Perencanaan Perkerasan Kaku dengan Metode AASHTO 1993 Studi Kasus Jalan Batanghari II Kabupaten Muaro Jambi
}

\author{
Sigit Kurniawan*, M. Asmuni Jatoeb, Susiana \\ Program Studi Teknik Sipil Universitas Batanghari JambiBatanghari \\ *Correspondence email: Sigitkurniawan2425@gmail.com
}

\begin{abstract}
Abstrak. Ruas jalan Batanghari II merupakan jalan Nasional yang menghubungkan Kota Jambi dengan Kabupaten Tanjung Jabung Timur. Jalan ini membentang sepanjang $33 \mathrm{~km}$ dari perbatasan Kota Jambi - Kabupaten Muaro Jambi hingga Zona Lima (simpang plabi) Kabupaten Tanjung Jabung Timur. Ruas jalan ini merupakan penghubung sektor ekonomi, sosial dan budaya Kabupaten Tanjung Jabung Timur, Kabupaten Muaro Jambi dan Kota Jambi. Kendaraan yang melintas pada ruas jalan Batanghari II didominasi oleh kendaraan truk kecil maupun besar pengangkut hasil ekonomi dan hasil bumi lainnya. Kondisi jalan Batanghari II pada STA 18+500 merupakan perkerasan lentur yang telah hancur permukaannya hingga lapisan pondasi di bawahnya. Pada studi ini akan direncanakan perkerasan kaku dengan metode AASHTO 1993. Perencanaan dengan panjang jalan 3,6 km dan lebar 7 meter, dengan perencanaan $C B R$ tanah dasar 6\%, dengan nilai W18 dalam setahun sebesar 455.664,051. Pada studi ini didapat nilai $E S A L$ dalam 30 tahun sebesar 30.273.794, $429 E S A L$, dengan tepal pelat beton $28 \mathrm{~cm}$. Dengan jenis sambungan perkerasan bersambung dengan tulangan dengan panjang pelat 10 meter, dipasang tulangan wiremesh M10-150 mm. Serta dipasang tulangan Tie Bar Ø16 mm dengan panjang $700 \mathrm{~mm}$ dan jarak $750 \mathrm{~mm}$. Serta tulangan Dowel Ø36 mm dengan panjang $450 \mathrm{~mm}$ dan jarak $300 \mathrm{~mm}$.
\end{abstract}

Kata Kunci : AASHTO 1993, Perkerasan Kaku, Perkerasan Jalan, ESAL

\section{PENDAHULUAN}

Ruas jalan Batanghari II ini merupakan penghubung sektor ekonomi, sosial dan budaya Kabupaten Tanjung Jabung Timur, Kabupaten Muaro Jambi dan Kota Jambi. Serta terdapat pelabuhan, hasil tambang dan timbunan batu bara, sehingga terdapat pula kendaraan-kendaraan perusahaan tambang yang melintasi ruas jalan Batanghari II tersebut. Kendaraan yang melintas pada ruas jalan Batanghari II didominasi oleh kendaraan truk kecil maupun besar pengangkut hasil ekonomi seperti sawit, kelapa, dan hasil bumi lainnya. Kondisi jalan yang baik akan meningkatkan produktifitas serta menurunkan biaya perjalanan sehingga tercapai kesejahteraan daerah yang dilintasi jalan tersebut.

Kondisi jalan Batanghari II pada STA 18+500 merupakan perkerasan lentur yang telah hancur permukaannya hingga lapisan pondasi di bawahnya. dan ketika terjadi hujan terdapat genangan air yang tertampung pada perkerasan sehingga air tidak bisa kemana-mana hingga kering sendiri, karena terdapat lubang-lubang akibat beban pada roda kendaraan, sehingga jalan menjadi becek dan bisa mengakibatkan antrian akan membuat perjalanan menempuh waktu lebih lama dari sebelumnya. Ditambah lagi kendaraan berat juga melintas sehingga jalan akan semakin rusak parah, kenyamanan dan keamanan pun juga turut diperhitungkan guna keselamatan berlalu lintas.

Berdasarkan permasalahan di atas dapat disimpulkan bahwa perlu dilakukan peningkatan ruas jalan Batanghari II menjadi perkerasan kaku. Sehingga penulis mencoba merencanakan perkerasan kaku dengan metode AASHTO 1993

Rumusan masalah sebagai berikut :

1. Berapakah tebal pelat beton yang dibutuhkan pada perencanaan rigid pavement metode AASHTO 1993 ?

2. Berapakah kebutuhan tulangan pelat beton dalam perencanaan?

Tujuan studi yang ingin dicapai adalah sebagai berikut :

1. Meningkatkan struktur perkerasan lentur menjadi perkerasan kaku dengan menggunakan metode AASHTO 1993 sebagai alternatif terhadap kerusakan jalan selama ini akibat beban lalu lintas.

2. Menghitung tebal pelat beton yang dibutuhkan pada perkerasan kaku dengan metode AASHTO 1993.

3. Menghitung tulangan yang dibutuhkan dalam perkerasan kaku.

\section{Perencanaan Dengan Metode AASHTO 1993}

- Analisa lalu lintas. Mencakup umur rencana, LHR, pertumbuhan lalulintas, vehicle damage factor

- Traffic Design

$\mathrm{W}_{18}=\sum_{\mathrm{N} 1}^{\mathrm{Nn}} L_{\mathrm{J}} \times V D F_{\mathrm{J}} \times \mathrm{D}_{\mathrm{D}} \times \mathrm{D}_{\mathrm{L}} \times 365$

Dimana :

$\mathrm{W}_{18}=$ Traffic Design pada lajur lalu lintas, Equivalent Single Axle Load. 
$\mathrm{LHR}_{\mathrm{j}}=\mathrm{Jumlah}$ lalu lintas harian rata-rata 2 arah untuk jenis kendaraan $\mathrm{j}$.

$\mathrm{VDF}_{\mathrm{j}}=$ Vehicle Damage Factor untuk jenis kendaraan j.

$\mathrm{D}_{\mathrm{D}} \quad=$ Faktor Distribusi Arah.

$\mathrm{D}_{\mathrm{L}} \quad=$ Faktor Distribusi Lajur.

N1 = Lalu lintas pada tahun pertama jalan dibuka.

$\mathrm{Nn}=$ Lalu lintas pada akhir umur rencana.

Lalu lintas kumulatif sebagai berikut :

$\mathrm{W}_{\mathrm{t}}=\mathrm{W}_{18} \times \frac{(1+\mathrm{i})^{\mathrm{n}}-1}{\mathrm{i}}$

Dimana :

$\mathrm{W}_{\mathrm{t}} \quad$ = Jumlah beban gandar tunggal standar kumulatif.

$\mathrm{W}_{18}=$ Beban gandar standar kumulatif selama 1 tahun.

$\mathrm{n} \quad=$ Umur pelayanan, atau umur rencana UR (tahun).

$\mathrm{i} \quad=$ Perkembangan lalu lintas $(\%)$.

- Serviceability. Nilai serviceability ini diberikan dalam beberapa tingkatan antara lain:

a). Initial Serviceability (open traffic) Po = 4,5.

b). Terminal Serviceability Index jalur.

Tabel 1. : Terminal serviceability index (pt).

\begin{tabular}{cc}
\hline $\begin{array}{c}\text { Terminal } \\
\text { Serviceability Level }\end{array}$ & $\begin{array}{c}\text { Percent of People Stating } \\
\text { Unacceptable }\end{array}$ \\
\hline 3,0 & 12 \\
2,5 & 55 \\
2,0 & 85 \\
\hline
\end{tabular}

\section{Sumber : AASHTO 1993}

c). Total loss of Serviceability : $\Delta \mathrm{PSI}=\mathrm{Po}-\mathrm{Pt}$.

- Reliability

\section{Sumber : AASHTO 1993}

Tabel 2. : Reliability (R) disarankan.

\begin{tabular}{lcc}
\hline \multirow{2}{*}{\begin{tabular}{c} 
Functional \\
\multicolumn{1}{c}{ Classification }
\end{tabular}} & \multicolumn{2}{c}{$\begin{array}{c}\text { Recomended Level of } \\
\text { Reliability }\end{array}$} \\
\cline { 2 - 3 } & Rrban $(\%)$ & Rural \\
\hline Jalan tol & $85-99,9$ & $80-99,9$ \\
Arteri & $80-99$ & $75-95$ \\
Kolektor & $80-95$ & $75-95$ \\
Lokal & $50-80$ & $50-80$ \\
\hline
\end{tabular}

- Standar normal deviate $\left(\mathrm{Z}_{\mathrm{R}}\right)$ berdasarkan nilai reliability yaitu berkisar 0,0 hingga $-3,750$. Standar deviation untuk rigid pavement : So $=0,30-0,40$.

- $\quad C B R$ dan Modulus Reaksi Tanah Dasar. $\mathrm{M}_{\mathrm{R}}=1.500 \times C B R$ dan $\mathrm{k}=\frac{\mathrm{M}_{\mathrm{R}}}{19,4}$.

Dimana :

$\mathrm{M}_{\mathrm{R}} \quad=$ Resilient modulus

$\mathrm{k} \quad=$ modulus of subgrade reaction 


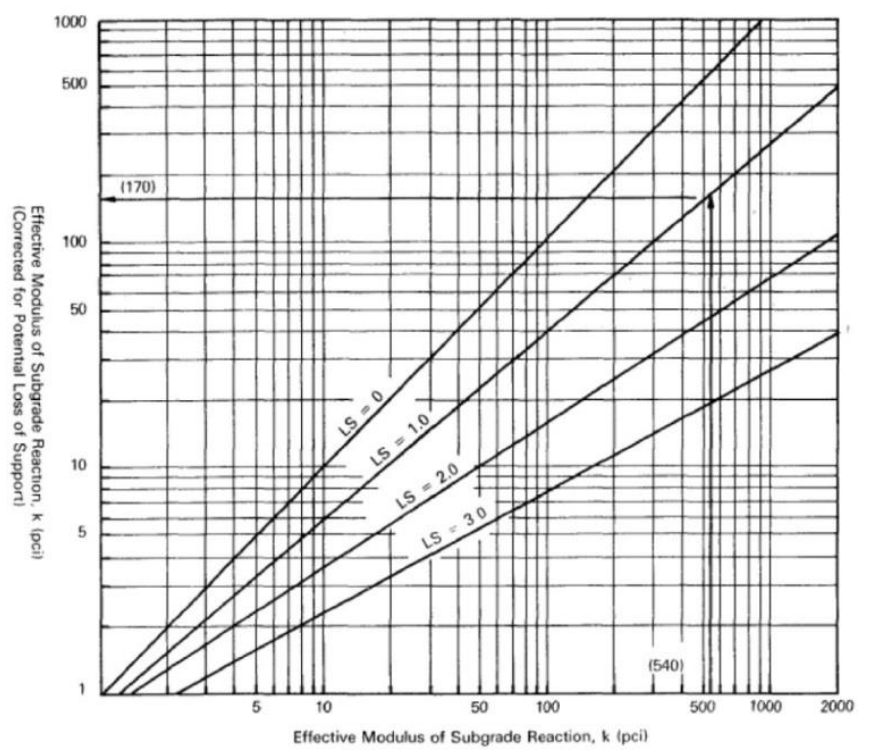

Gambar 1. : Correction of Effective Modulus of Subgrade Reaction for Potensial Loss of Subbase Support (6) Sumber : AASHTO 1993

Faktor Loss of Support (LS) memiliki nilai 0 - 3 .

- Modulus Elastisitas Beton $\mathrm{E}_{\mathrm{C}}=57000\left(\mathrm{f}_{\mathrm{c}}^{\prime}\right)^{0,5}$.

Dimana :

$\mathrm{E}_{\mathrm{C}} \quad=$ Modulus elatisitas beton ( $\mathrm{psi}$ ).

$f_{C}^{\prime} \quad=$ Kuat tekan beton, silinder (psi).

- Drainage Coefficient AASHTO 1993 memberikan kualitas drainase excellent, Good, Fair, Poor, dan Very poor.

- Persamaan Penentuan Tebal Pelat (D)

$$
\begin{aligned}
\log _{10} \mathrm{~W}_{18}= & \mathrm{Z}_{\mathrm{R}} \mathrm{S}_{0} 7,35 \log _{10}(\mathrm{D}+1)-0,06+\frac{\log _{10}\left[\frac{\Delta \mathrm{PSI}}{4,5-1,5}\right]}{1+\frac{1,624 \times 10^{7}}{(\mathrm{D}+1)^{8,46}}}+\left(4,22-0,32 \mathrm{p}_{\mathrm{t}}\right) \\
& \times \log _{10} \frac{\mathrm{S}_{\mathrm{C}} \mathrm{C}_{\mathrm{d}} \times\left[\mathrm{D}^{0,75}-1,132\right]}{215,63 \times \mathrm{J} \times\left[\mathrm{D}^{0,75}-\frac{18,42}{\left(\mathrm{E}_{\mathrm{c}}: \mathrm{k}\right)^{0,25}}\right]}
\end{aligned}
$$

Dimana :

$\mathrm{W}_{18}=$ Traffic design, Equivalent single axle load $($ ESAL $)$

$\mathrm{Z}_{\mathrm{R}} \quad=$ Standar normal deviasi

$\mathrm{S}_{\mathrm{o}} \quad=$ Standar deviasi

$\mathrm{D} \quad=$ Tebal pelat beton (inci)

$\Delta \mathrm{PSI}=$ Serviceability loss $=\mathrm{P}_{\mathrm{o}}-\mathrm{P}_{\mathrm{t}}$

$\mathrm{P}_{\mathrm{t}} \quad=$ Terminal serviceability index

$\mathrm{S}_{\mathrm{c}}$, $=$ Modulus of rupture sesuai spesifikasi pekerjaan (psi)

$\mathrm{C}_{\mathrm{d}} \quad=$ Drainage coefficient

$\mathrm{J} \quad=$ Load transfer coefficient

$\mathrm{E}_{\mathrm{c}} \quad=$ Modulus elastisitas (psi)

$\mathrm{k} \quad=$ Modulus reaksi tanah dasar (pci)

- Perencanaan Penulangan.

Perencanaan dengan Perkerasan beton semen bersambung dengan tulangan

$\mathrm{A}_{\mathrm{s}}=\frac{F \cdot L \cdot M \cdot g \cdot h}{2 \cdot \mathrm{f}_{\mathrm{s}}}$

Dimana :

As = luas penampang tulangan baja $(\mathrm{mm} 2 / \mathrm{m}$ lebar pelat $)$

fs $\quad=$ kuat-tarik ijin tulangan (MPa). Biasanya 0,6 kali tegangan leleh.

$\mathrm{g}=$ gravitasi ( $\mathrm{m} /$ detik2).

$\mathrm{h} \quad=$ tebal pelat beton $(\mathrm{m})$

$\mathrm{L} \quad=$ jarak antara sambungan yang tidak diikat dan/atau tepi bebas pelat $(\mathrm{m})$

$\mathrm{M} \quad$ = berat per satuan volume pelat $(\mathrm{kg} / \mathrm{m} 3)$

$\mathrm{F} \quad=$ koefisien gesek antara pelat beton dan pondasi bawah 
Tabel 3. : Recommended Friction Factors

\begin{tabular}{lc}
\hline \multicolumn{1}{c}{ Type of Material Beneath Slab } & Friction Factor $(\mathbf{F})$ \\
\hline Surface treatmen & 2,2 \\
Lime stabilization & 1,8 \\
Ashphal stabilization & 1,8 \\
Cement stabilization & 1,8 \\
River gravel & 1,5 \\
Crushed stone & 1,5 \\
Sandstone & 1,2 \\
Natural subgrade & 0,9
\end{tabular}

\section{- Tie Bar}

Menurut Pd.T-14-2003. Sambungan memanjang dengan batang ulir dengan mutu minimum BJTU- 24 dan berdiameter $16 \mathrm{~mm}$.

Tabel 4. : Tie Bar

\begin{tabular}{|c|c|c|c|c|c|c|c|c|c|c|}
\hline \multirow{2}{*}{$\begin{array}{c}\text { Jenis } \\
\text { dan } \\
\text { mutu } \\
\text { baja }\end{array}$} & \multirow[b]{2}{*}{$\begin{array}{c}\text { Tegangan } \\
\text { kerja (psi) }\end{array}$} & \multirow{2}{*}{$\begin{array}{c}\text { Tebal } \\
\text { perkerasan } \\
\text { (in) }\end{array}$} & \multicolumn{4}{|c|}{$\begin{array}{l}\text { Diameter batang } 1 / 2 \text { in } \\
\text { Jarak maximum (in) }\end{array}$} & \multicolumn{4}{|c|}{$\begin{array}{l}\text { Diameter batang } 5 / 8 \text { in } \\
\text { Jarak maximum (in) }\end{array}$} \\
\hline & & & $\begin{array}{l}\text { Panjang } \\
\text { (in) }\end{array}$ & $\begin{array}{c}\text { Lebar } \\
\text { lajur } 10 \\
\mathrm{ft}\end{array}$ & $\begin{array}{c}\text { Lebar } \\
\text { lajur } 11 \\
\text { ft }\end{array}$ & $\begin{array}{c}\text { Lebar } \\
\text { lajur } \\
12 \mathrm{ft}\end{array}$ & $\begin{array}{c}\text { Panjang } \\
\text { (in) }\end{array}$ & $\begin{array}{c}\text { Lebar } \\
\text { lajur } \\
10 \mathrm{ft}\end{array}$ & $\begin{array}{l}\text { Lebar } \\
\text { lajur } \\
11 \mathrm{ft}\end{array}$ & $\begin{array}{l}\text { Lebar } \\
\text { lajur } \\
12 \mathrm{ft}\end{array}$ \\
\hline Grade & 30.000 & 6 & 25 & 48 & 48 & 48 & 30 & 48 & 48 & 48 \\
\hline 40 & & 7 & 25 & 48 & 48 & 48 & 30 & 48 & 48 & 48 \\
\hline & & 8 & 25 & 48 & 44 & 40 & 30 & 48 & 48 & 48 \\
\hline & & 9 & 25 & 48 & 40 & 38 & 30 & 48 & 48 & 48 \\
\hline & & 10 & 25 & 48 & 38 & 32 & 30 & 48 & 48 & 48 \\
\hline & & 11 & 25 & 35 & 32 & 29 & 30 & 48 & 48 & 48 \\
\hline & & 12 & 25 & 32 & 29 & 26 & 30 & 48 & 48 & 48 \\
\hline
\end{tabular}

Sumber : literatur/makalah UI dalam Ari Suryawan (2016)

- Dowel (Ruji)

Tabel 5. : Diameter ruji

\begin{tabular}{ccc}
\hline No & Tebal pelat beton, $\mathbf{h}(\mathbf{m m})$ & Diameter ruji $\mathbf{( m m})$ \\
\hline 1 & $125<\mathrm{h} \leq 140$ & 20 \\
2 & $140<\mathrm{h} \leq 160$ & 24 \\
3 & $160<\mathrm{h} \leq 190$ & 28 \\
4 & $190<\mathrm{h} \leq 220$ & 33 \\
5 & $220<\mathrm{h} \leq 250$ & 36 \\
\hline
\end{tabular}

Sumber : Pd.T-14-2003

Tabel 6. : Ukuran dan jarak batang dowel (ruji) yang disarankan

\begin{tabular}{cccccccc}
\hline \multirow{2}{*}{$\begin{array}{c}\text { Tebal Pelat } \\
\text { Perkerasan }\end{array}$} & \multicolumn{9}{c}{ Diameter } & \multicolumn{2}{c}{ Panjang } & \multicolumn{2}{c}{ Jarak } \\
\cline { 2 - 7 } & mm & inci & mm & inci & mm & inci & mm \\
\hline 6 & 150 & $3 / 4$ & 19 & 18 & 450 & 12 & 300 \\
7 & 175 & 1 & 25 & 18 & 450 & 12 & 300 \\
8 & 200 & 1 & 25 & 18 & 450 & 12 & 300 \\
9 & 225 & $11 / 4$ & 32 & 18 & 450 & 12 & 300 \\
10 & 250 & $11 / 4$ & 32 & 18 & 450 & 12 & 300 \\
11 & 275 & $11 / 4$ & 32 & 18 & 450 & 12 & 300 \\
\hline 12 & 300 & $11 / 2$ & 38 & 18 & 450 & 12 & 300 \\
13 & 325 & $11 / 2$ & 38 & 18 & 450 & 12 & 300 \\
14 & 350 & $11 / 2$ & 38 & 18 & 450 & 12 & 300 \\
\hline
\end{tabular}

Sumber : principles of pavement design by yoder \& witczak, 1975 dalam Shirley L. Hendarsin, 2000 
Sigit Kurniawan, M. Asmuni Jatoeb dan Susiana, Perencanaan Perkerasan Kaku dengan Metode AASHTO 1993Studi Kasus Jalan Batanghari II Kabupaten Muaro Jambi

\section{METODE}

Secara ringkas penelitian ini bisa dilihat dari bagan alir penelitian berikut :

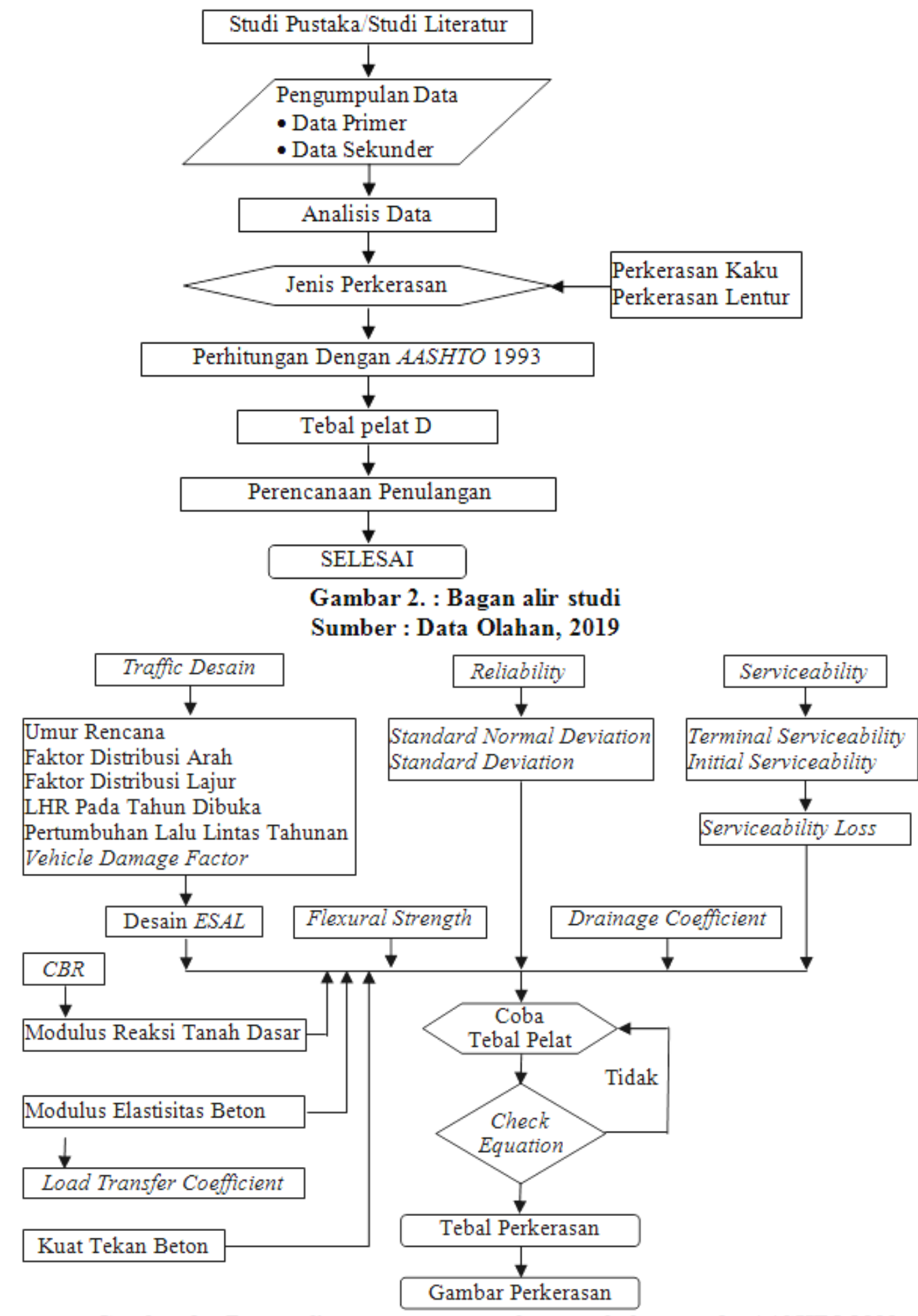

Gambar 3. : Bagan alir perencanaan perkerasan kaku metode AASHTO 1993 Sumber : Data Olahan, 2019

HASIL DAN PEMBAHASAN

Modulus Reaksi Tanah Dasar

Nilai $C B R$ ditetapkan $6 \%$.

$\mathrm{M}_{\mathrm{R}} \quad=1500 \times C B R=1500 \times 6=9000$

$\mathrm{K} \quad=\frac{\mathrm{M}_{\mathrm{R}}}{19,4}=\frac{9000}{19,4}=464 \mathrm{pci}$

Lapis subbase : Agregat kelas B 
Sigit Kurniawan, M. Asmuni Jatoeb dan Susiana, Perencanaan Perkerasan Kaku dengan Metode AASHTO 1993Studi Kasus Jalan Batanghari II Kabupaten Muaro Jambi

Loss of support $(\mathrm{LS})=3$

Koreksi effective modulus of subgrade reaction, dengan gambar 4.1. di bawah didapat : $\mathrm{k}=18$ pci

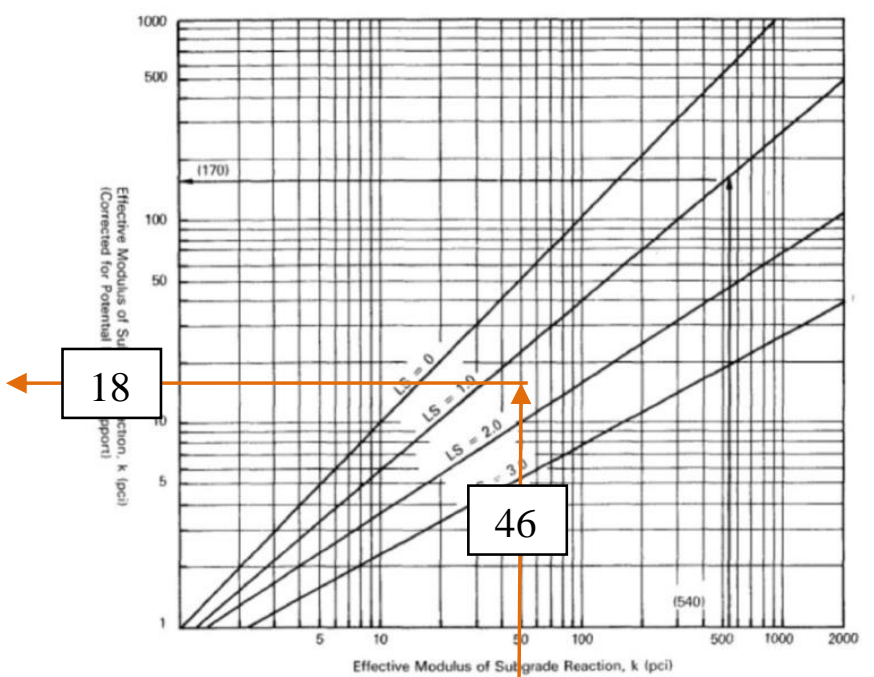

Gambar 4. : Effective modulus of subgrade reaction, $\mathrm{k}$ (pci)

\section{Traffic Design}

Tabel 7. : LHR, VDF, dan Perhitungan Desain Lalulintas (ESAL)

\begin{tabular}{llccccccc}
\hline No & \multicolumn{1}{c}{ Jenis Kendaraan } & Gol & LHR & VDF & DD & DL $\begin{array}{c}\text { Hari } \\
\text { Dalam } \\
\text { Setahun }\end{array}$ & $\mathbf{W}_{\mathbf{1 8}}$ \\
\hline 1 & Kendaraan Ringan & 2 & 1457 & 0,0024 & 0,5 & 1 & 365 & 625,428 \\
2 & Angkutan Penumpang & 3 & 35 & 0,0024 & 0,5 & 1 & 365 & 15,024 \\
3 & Pick Up & 4 & 648 & 0,0099 & 0,5 & 1 & 365 & 1175,792 \\
4 & Bus kecil & $5 \mathrm{a}$ & 1 & 0,2397 & 0,5 & 1 & 365 & 43,740 \\
6 & Truk ringan 2 sumbu & $6 \mathrm{a}$ & 467 & 0,2397 & 0,5 & 1 & 365 & 20426,455 \\
7 & Truk sedang 2 sumbu & $6 \mathrm{~b}$ & 428 & 3,0420 & 0,5 & 1 & 365 & 237611,645 \\
8 & Truk 3 sumbu & $7 \mathrm{~m}$ & 411 & 2,6100 & 0,5 & 1 & 365 & 195765,968 \\
\hline & & \multicolumn{3}{c}{$\sum \mathrm{W}_{18}=$} \\
\hline
\end{tabular}

Sumber : Hasil Perhitungan 2020

Didapat nilai $\mathrm{W}_{18}$ dalam setahun, $\mathrm{W}_{18}=455.664,051$

$$
\mathrm{W}_{\mathrm{t}}=\mathrm{W}_{18} \times \frac{(1+\mathrm{i})^{\mathrm{n}}-1}{\mathrm{i}}
$$

Umur rencana 30 tahun :

$\mathrm{W}_{\mathrm{t}}=455.664,051 \times \frac{(1+0,05)^{30}-1}{0,05}=30.273 .794,429 E S A L$

\section{Modulus Elastisitas Beton}

Digunakan $\mathrm{f}_{\mathrm{C}}^{\prime}=350 \mathrm{~kg} / \mathrm{cm}^{2}$, konversi ke satuan psi $=350 \times 14,22=4977 \mathrm{psi}$.

Maka, Ec $=57000\left(f_{c}^{\prime}\right)^{0,5}=57000(4977)^{0,5}=4.021 .228 \mathrm{psi}$

\section{Tabel Parameter dan Desain Yang Digunakan}

Tabel 8. : Parameter dan data yang digunakan dalam perencanaan

\begin{tabular}{clccc}
\hline NO & \multicolumn{1}{c}{ Parameter } & AASHTO & Desain & Keterangan \\
1 & Umur Rencana & - & 30 & 20 - 40 Tahun \\
2 & Lalu-lintas, ESA & - & 30273794,429 & > 30 Juta ESAL \\
3 & Terminal Serviceability (pt) & $2,0-3,0$ & 2,0 & Index permukaan perkerasan awal \\
4 & Initial Serviceability (po) & 4,5 & 4,5 & Untuk rigid pavement \\
5 & Serviceability Loss ( $\Delta$ PSI) & po $-\mathrm{pt}$ & 2,5 & \\
6 & Reability (R) & $75-99,9$ & 95 & $-1,645$ \\
7 & Standar Normal Deviation (Zr) & $-0,674 \mathrm{sd}-1,645$ & 0,35 & \\
8 & Standar Deviation (So) & $0,30-0,40$ &
\end{tabular}


Sigit Kurniawan, M. Asmuni Jatoeb dan Susiana, Perencanaan Perkerasan Kaku dengan Metode AASHTO 1993Studi Kasus Jalan Batanghari II Kabupaten Muaro Jambi

9 Modulus Reaksi Tanah Dasar (k)

10 Modulus Elastisitas Beton (Ec)

11 Flexural Strength $\left(\mathrm{S}^{\prime} \mathrm{c}\right)$

12 Drainage Coefficient $(\mathrm{Cd})$

13 Load Transfer Coefficient (J)

Sumber : Data perencanaan 2020
$6 \%$

4021227,8

45

$1,20-1,15$

$2,5-3,1$
Berdasarkan CBR $=6^{*}$ )

Berdasarkan : $\mathrm{f}^{\prime} \mathrm{c}=350 \mathrm{~kg} / \mathrm{cm}^{\wedge} 2$

Berdasarkan : $\mathrm{S}^{\prime} \mathrm{c}=45 \mathrm{~kg} / \mathrm{cm}^{\wedge} 2$

Baik

Join dengan dowel

Perhitungan Tebal Perkerasan Kaku Metode AASHTO 1993

$$
\begin{aligned}
& \log _{10} \mathrm{~W}_{18}= \mathrm{Z}_{\mathrm{R}} \mathrm{S}_{0} 7,35 \log _{10}(\mathrm{D}+1)-0,06+\frac{\log _{10}\left[\frac{\Delta \mathrm{PSI}}{4,5-1,5}\right]}{1+\frac{1,624 \times 10^{7}}{(\mathrm{D}+1)^{8,46}}}+\left(4,22-0,32 \mathrm{p}_{\mathrm{t}}\right) \times \\
& \log _{10} \frac{\mathrm{S}_{\mathrm{c}} \mathrm{C}_{\mathrm{d}} \times\left[\mathrm{D}^{0,75}-1,132\right]}{215,63 \times \mathrm{J} \times\left[\mathrm{D}^{0,75}-\frac{18,42}{\left.\left(\mathrm{E}_{\mathrm{c}}: \mathrm{k}\right)^{0,25}\right]}\right.} \\
& \operatorname{LogWt}=-1,645 \times 0,35 \times 7,35 \log _{10}(\mathrm{D}+1)-0,06+\frac{\log _{10}\left[\frac{2,5}{4,5-1,5}\right]}{1+\frac{1,624 \times 10^{7}}{(\mathrm{D}+1)^{8,46}}}+ \\
&(4,22-0,32 \times 2) \times \log _{10} \frac{640 \times 1,175 \times\left[\mathrm{D}^{0,75}-1,132\right]}{215,63 \times 2,8 \times\left[\mathrm{D}^{0,75}-\frac{18,42}{(4.020 .228: 18)^{0,25}}\right]}
\end{aligned}
$$

Dari hasil perhitungan trial and error di atas dapatlah hasil nilai $\mathrm{D}=11,04$ inci. yaitu $28 \mathrm{~cm}$ dengan umur rencana 30 tahun.

\section{Perhitungan Penulangan}

Data yang diketahui :

- Tebal pelat (h)

$: 280 \mathrm{~mm}$

- Lebar pelat (b)

$: 3,5 \mathrm{~m}$

- Panjang pelat (p)

$: 10 \mathrm{~m}$

- Koefisien gesek (F)

: 1,5 (batu pecah)

- Tegangan tarik baja izin (fs)

: $240 \mathrm{MPa}$

\section{Perkerasan Bersambung Dengan Tulangan}

1. Tulangan memanjang

$$
\begin{aligned}
& A_{s}=\frac{\text { F. L.M.g.h }}{2 \cdot f_{s}} \\
& A_{s}=\frac{1,5 \times 10 \times 2400 \times 9,81 \times 0,28}{2 \times 240}=206,01 \mathrm{~mm}^{2} / \mathrm{m} \\
& A_{s} \min =0,0014 \times 280 \times 1000=392 \mathrm{~mm}^{2} / \mathrm{m}
\end{aligned}
$$

2. Tulangan melintang

$$
\begin{aligned}
& A_{s}=\frac{\text { F. L.M.g.h }}{2 . f_{s}} \\
& A_{s}=\frac{1,5 \times 3,5 \times 2400 \times 9,81 \times 0,28}{2 \times 240}=72,10 \mathrm{~mm}^{2} / \mathrm{m} \\
& A_{s} \min =0,0014 \times 280 \times 1000=392 \mathrm{~mm}^{2} / \mathrm{m}
\end{aligned}
$$

\section{Batang Pengikat (Tie Bar)}

Menurut Pd.T-14-2003 dengan mutu minimum BJTU- 24 dan berdiameter $16 \mathrm{~mm}$ dengan jarak $75 \mathrm{~cm}$ atau dengan rumus berikut ini :

$$
\begin{aligned}
\text { At } & =204 \times \mathrm{b} \times \mathrm{h} \\
& =204 \times 3,5 \times 0,28 \\
& =199,92 \mathrm{~mm}^{2} \\
1 & =(38,3 \times \varphi)+75 \\
& =(38,3 \times 16)+75 \\
& =687,80 \mathrm{~mm}
\end{aligned}
$$


Sigit Kurniawan, M. Asmuni Jatoeb dan Susiana, Perencanaan Perkerasan Kaku dengan Metode AASHTO 1993Studi Kasus Jalan Batanghari II Kabupaten Muaro Jambi

Sedangkan menurut literatur/makalah UI dalam Ari Suryawan (2016) berdasarkan tabel 2.13 dengan grade 40 dicoba tulangan D1/2 inci $(12,70 \mathrm{~mm})$ dengan panjang 25 inci $(635 \mathrm{~mm})$ dan jarak maksimum D29 inci $(736 \mathrm{~mm})$.

\section{Dowel}

Menurut Pd.T-14-2003 berdasarkan tabel 2.14 yaitu D36 mm. Sedangkan menurut principles of pavement design by yoder \& witczak, 1975 dalam Shirley L.Hendarsin (2000) berdasarkan tabel 2.15 yaitu D32 mm

\section{Pembahasan}

\section{Tebal Pelat Beton}

Dari hasil perhitungan didapat tebal pelat beton $28 \mathrm{~cm}$

Sumber : Gambar olahan tugas akhir, 2020

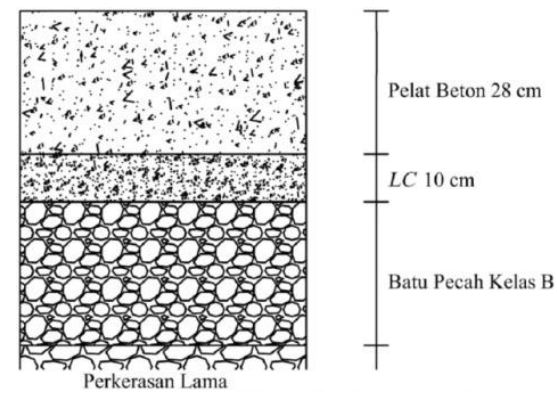

Gambar 5. : Tebal perkerasan

\section{Kebutuhan Tulangan}

Dari hasil kebutuhan tulangan memanjang dan melintang $\mathrm{A}_{\mathrm{s}}=392 \mathrm{~mm} / \mathrm{m}$, dapat digunakan tulangan wiremesh M10 $-150 \mathrm{~mm}=523 \mathrm{~mm}^{2} / \mathrm{m}$

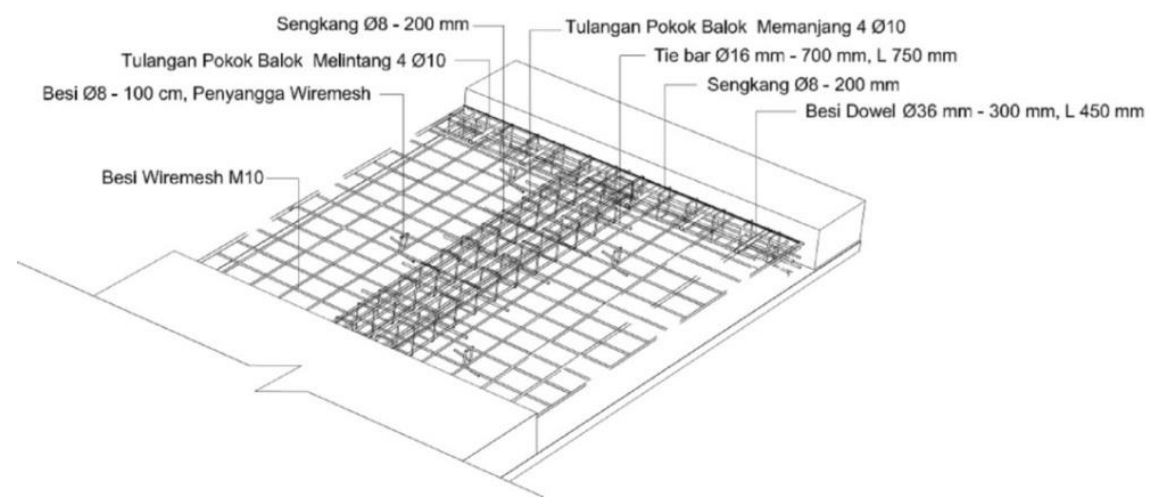

\section{Sumber : Gambar olahan tugas akhir, 2020}

Gambar 6. : Detail tulangan

\section{Batang Pengikat (Tie Bar)}

Maka dari hasil kedua literatur tersebut, penulis mencoba menggunakan menurut Pd.T-14-2003 tulangan sebagai berikut :

- Diameter tulangan : $16 \mathrm{~mm}$

- Panjang : $\quad: 700 \mathrm{~mm}$

- Jarak tulangan $: 750 \mathrm{~mm}$ 


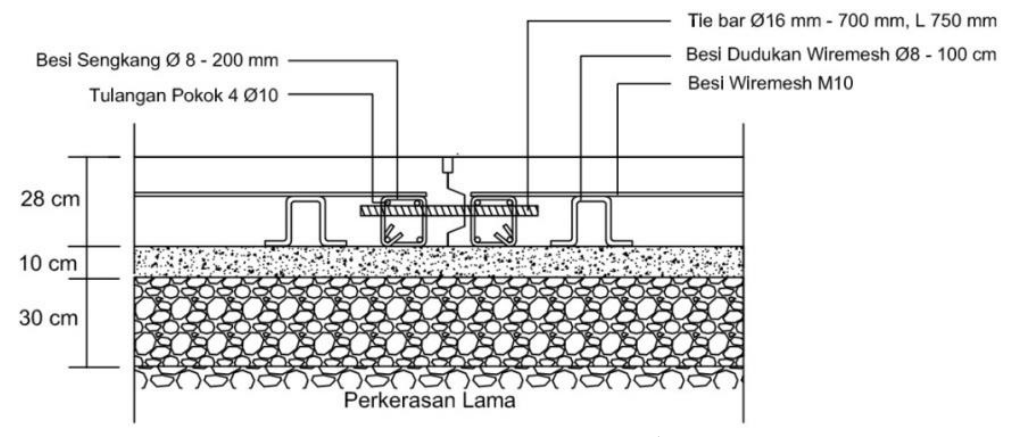

Sumber : Gambar olahan tugas akhir, 2020

Gambar 7. : Detail tie bar

Dowel

Maka dari hasil kedua literatur tersebut, penulis mencoba menggunakan menurut Pd.T-14-2003 tulangan sebagai berikut :

- Diameter tulangan : $36 \mathrm{~mm}$

- Panjang : $450 \mathrm{~mm}$

- Jarak tulangan : $\quad 300 \mathrm{~mm}$

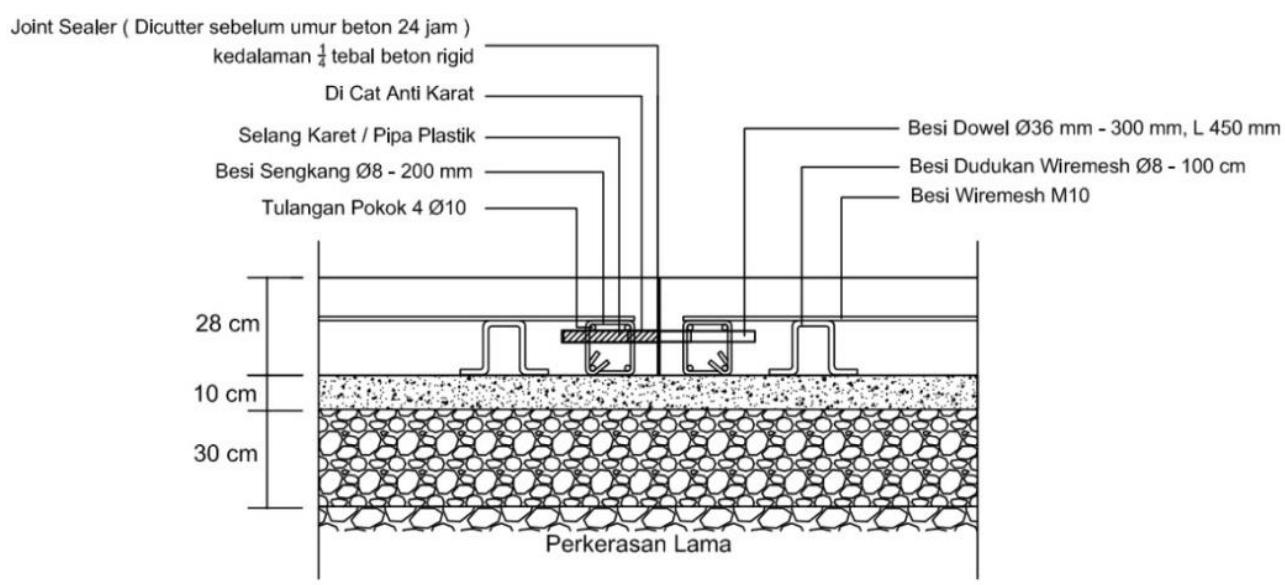

Gambar 8. : Detail dowel

Sumber : Gambar olahan tugas akhir, 2020

\section{SIMPULAN}

Berdasarkan hasil perhitungan pada perencanaan perkerasan kaku dengan metode AASHTO 1993 pada jalan Batanghari II, Diperolehlah kesimpulan antara lain :

1. Dengan nilai $E S A L$ umur rencana 30 tahun $=30.273 .794,429$ juta $E S A L$ didapatlah tebal pelat beton $280 \mathrm{~mm}$

2. Perencanaan menggunakan perkerasan bersambung dengan tulangan dengan lebar pelat 3,5 m dan panjang pelat 10 $\mathrm{m}$ dengan kebutuhan tulangan digunakan wiremesh M10 - 150mm.

3. Sambungan memanjang dengan batang pengikat (tie bar) digunakan baja ulir $16 \mathrm{~mm}$ dengan panjang $700 \mathrm{~mm}$ serta jarak tulangan $750 \mathrm{~mm}$.

4. Sambungan melintang dengan ruji/dowel digunakan tulangan polos $36 \mathrm{~mm}$ dengan panjang $450 \mathrm{~mm}$ serta jarak tulangan $300 \mathrm{~mm}$.

\section{DAFTAR PUSTAKA}

AASHTO, 1993. AASHTO Guide For Design Of Pavement Structures. Wasington DC, America.

Departemen Permukiman Dan Prasarana Wilayah, Perencanaan perkerasan jalan beton semen, Pd T-14-2003.

Departemen Permukiman Dan Prasarana Wilayah, Survai Pencacahan Lalu Lintas dengan cara Manual, Pd.T-192004-B.

Hendarsin Shirley L, 2000. Penuntun Praktis Perencanaan Teknik Jalan Raya. Politeknik Negeri Bandung Jurusan Teknik Sipil, Bandung.

Peraturan Pemerintah Republik Indonesia. No.34 Tahun 2006, Tentang Jalan.

Perencanaan tebal lapis tambah perkerasan lentur dengan metode lendutan. Pd.T-05-2005-B.

Sukirman Silvia, 2010, Perencanaan Tebal Struktur Perkerasan Lentur, Penerbit Nova, Bandung. 
Sigit Kurniawan, M. Asmuni Jatoeb dan Susiana, Perencanaan Perkerasan Kaku dengan Metode AASHTO 1993Studi Kasus Jalan Batanghari II Kabupaten Muaro Jambi

Suryawan Ari, 2016. Perkerasan Jalan Beton Semen Portland (Rigid Pavement), Beta Offset, Yogyakarta. Undang Undang Republik Indonesia, Nomor 22 tahun 2009, Tentang Lalu Lintas dan Angkutan Jalan 